\title{
Evaluation of Hormonal Changes Among Saudi Females With Primary and Secondary Infertility at Tertiary Hospital in Riyadh: A Cross-Sectional Study
}

\author{
Tarig Karar ${ }^{1}$, Mohamed Abdul Fattah, Heba Alwehaibi', \\ Ruba Albabtain', Khawlah Almuhalhil', Fatmah Othman² \\ ${ }^{1}$ Clinical Laboratory Department, College of Applied Medical Sciences, King \\ Saud bin Abdulaziz University for Health Sciences, Riyadh, Saudi Arabia King \\ Abdullah International Medical Research Center, Riyadh, Saudi Arabia. \\ ${ }^{2}$ King Abdullah International Medical Research Center, Riyadh, Saudi Arabia. \\ Research Unit, College of Applied Medical Sciences, King Saud bin Abdulaziz \\ University for Health Sciences, Riyadh, Saudi Arabia
}

\section{ABSTRACT}

Infertility is considered an emerging issue among the Saudi population in which it accounts for around 2.2\% of cases in Saudi Arabia. Numerous studies examined the association between reproductive hormone changes and infertility; however, there is still a gap in the literature regarding the hormonal changes among Saudi female. Therefore, this study aimed to evaluate the reproductive hormonal changes in females with infertility. A rcross-sectional study have been carried out at King Abdulaziz Medical City (KAMC) hospital in Riyadh from 2017 through 2018. All Saudi females with primary and secondary infertility aged between 20 and 35 years were included in this study. The blood level of folliclestimulating hormone (FSH), luteinizing hormone (LH), estrogen, prolactin, and progesterone were obtained from the medical record of those patients. A total of 81 infertile women were recruited for this study. 57(70\%) of them were with primary infertility, where 24(30\%) females were with secondary infertility. Patients with secondary infertility were older than patients with primary infertility $(\mathrm{P}<0.001)$. Similarly, the percentage of obese patients was higher compared to other Body Mass Index categories, and that was different between patients with primary and secondary infertility ( $\mathrm{p}=0.02$ ). Conclusion: This finding provides insight into infertility classification among Saudi infertile women and could be used as the first step in exploring infertility causes in all regions of Saudi Arabia in addition to other factors.

KEY WORDS: PRIMARY INFERTILITY, SECONDARY INFERTILITY, SAUDI FEMALES.

\section{ARTICLE INFORMATION}

Received 13th Oct 2020 Accepted after revision 24th Dec 2020 Print ISSN: 0974-6455 Online ISSN: 2321-4007 CODEN: BBRCBA

Thomson Reuters ISI Web of Science Clarivate Analytics USA and Crossref Indexed Journal

\section{Clarivate
Analytics}

NAAS Journal Score 2020 (4.31)

A Society of Science and Nature Publication,

Bhopal India 2020. All rights reserved.

Online Contents Available at: http//www.bbrc.in/

Doi: http://dx.doi.org/10.21786/bbrc/13.15/42

\section{INTRODUCTION}

Infertility considers one of the health problems that occurred during the reproductive age, affecting about $10-15 \%$ of couples seeking to achieve pregnancy in worldwide. It defined as a failure to achieve a natural pregnancy after 12 months or more of regular unprotected sexual intercourse. World Health Organization (WHO) has categorized infertility as primary and secondary. WHO describes primary infertility as the incapability to ever bear a baby, because of the incapability of being pregnant or the incapability to carry a pregnancy to live birth, while 
secondary infertility denotes the incapability to conceive after pregnancy. It was reported that the prevalence of infertility worldwide ranged between $5 \%$ and $25.7 \%$, and it had been estimated that the average incidence rate of infertility in Saudi Arabia approximately more than $2.2 \%$ of the population, amounting to 30,000 couples . According to a previous study conducted in Riyadh Military Hospital in Saudi Arabia, the average of infertile patients with primary infertility was about $58.6 \%$, while $41.4 \%$ are having secondary infertility.

Infertility causes are divided into several factors, which can be categorized as male factors, female factors, the combination of male and female factors, and unexplained or unknown infertility factors. Approximately about $50 \%$ of all infertility cases have a female infertility factors. Thus female infertility factors contributes for approximately one-third of all infertility. Biological and psychological factors play a critical role in minimizing fertility rate. Hormones such as estrogen, progesterone, prolactin, follicle stimulating hormone (FSH) and luteinizing hormone (LH) can greatly affect female fertility. other factors that could contribute to female infertility are ovulation disorders, fallopian tubes damage, and cervical factors. Numerous studies have shown the association between reproductive hormone changes and infertility, however, there is still a gap in the literature regarding the hormonal changes among Saudi female. Therefore, this study aimed to evaluate the hormonal changes in Saudi females with primary and secondary infertility and compare reproductive hormones between the two groups.

\section{METHODS}

Study Design and Population: A retrospective crosssectional study was conducted at Obstetrics and Gynecology Department at King Abdulaziz Medical City (KAMC) hospital in Riyadh, Saudi Arabia, during the period from September 2017 to January 2018. KAMC provides all types of care to patients, starting from primary healthcare up to specialized tertiary care, with a bed capacity of 1501 . We collected information on female patients diagnosed with infertility between the ages of 20 and 35 years who attended the obstetrics and gynecology department. We excluded patients who have cancer from the study population and those patients who older than 35 years to limit the effect of those two confounders in our analysis.

Study Variables: Patients' medical records was used to collect the data on the demographic information, clinical diagnosis, and laboratory results. The following hormonal parameter was collected from each patient: the serum level of LH, FSH, estrogen, prolactin, and progesterone. Those level were analyzed using a fully automated Immunoassay analyzer that uses chemiluminescent magnetic microparticle immunoassay. We categorized the age into two age groups ( $\leq 30$ years and $>30$ years), the Body Mass Index (BMI) into (underweight, normal, overweight, and obsess, and the duration into $\leq 5$ years or $>5$ years. For the diagnosis, we grouped the recorded diagnosis into: ovulation problems, uterine problems, male factor, and unexplained causes.

Table 1. Clinical data of all patients with infertility, those with primary, and secondary infertility.

\begin{tabular}{|c|c|c|c|c|}
\hline Variables & $\begin{array}{l}\text { All patients } \\
\text { Number(\%) }\end{array}$ & $\begin{array}{c}\text { Patients with } \\
\text { primary infertility } \\
\text { Number(\%) }\end{array}$ & $\begin{array}{c}\text { Patients with } \\
\text { secondary infertility } \\
\text { Number( } \%)\end{array}$ & P value* \\
\hline Age categories & & & & $<0.001$ \\
\hline$\leq 30$ years & $41(51)$ & $36(63)$ & $5(21)$ & \\
\hline$>30$ years & $40(49)$ & 21(37) & 19(79) & \\
\hline BMI & & & & 0.022 \\
\hline Underweight & $5(6)$ & $5(9)$ & $0(0)$ & \\
\hline Normal & $17(21)$ & $14(24)$ & $3(13)$ & \\
\hline overweight & $22(17)$ & 10(17) & $12(50)$ & \\
\hline obese & $37(46)$ & 28(49) & $9(37)$ & \\
\hline Duration of infertility in years & & & & 0.061 \\
\hline$\leq 5$ years & $41(51)$ & $25(44)$ & $16(67)$ & \\
\hline$>5$ years & $40(49)$ & $32(56)$ & $8(33)$ & \\
\hline
\end{tabular}

Statistical Methods: Statistical analysis of study variables was carried out using SPSS software version 16. descriptive analysis was carried out in which we used the mean and standard deviation(SD) to describe the continuous variable if normally distributed otherwise we used median and interquartile range (IQR) We used an independent t-test to compare the hormonal parameter among patients with primary and secondary infertility if normally distributed, and we used the Mann-Whitney test for skewed variables. For categorical variable comparison, we used the chi-square test, and Fisher exact test to obtain the $p$-values. Results with $p$ values of $<0.05$ were considered significant. 
Ethical Considerations: This study was approved by the Institutional Review Board (IRB) of the National Guard Health Affairs (NGHA (Riyadh, protocol number SP $17 / 223 / R$

\section{RESULTS}

In total, 81 patients were included in this study. The mean age of the study population was $30 \pm 3$ years. 57 $(70 \%)$ of them were diagnosed with primary infertility, where 24 (30\%) were diagnosed with secondary infertility. Table 1 demonstrates the clinical variable among all patients and for those with primary and secondary infertility. Patients with secondary infertility were older than patients with primary infertility (79\% patients with secondary infertility were above 30 years compared to $37 \%$ with primary infertility $\mathrm{p}$ value $<0.001$ ). Similarly, the percentage of obese patients was higher compared to other BMI categories, and that was different between patients with primary and secondary infertility ( $p$ value $=0.02$ ).

Table 2. Hormonal level among all patients with infertility, those with primary, and secondary infertility.

\begin{tabular}{|l|c|c|c|c|}
\hline Parameter & $\begin{array}{c}\text { All patients } \\
\text { Median (IQR) }\end{array}$ & $\begin{array}{c}\text { Patients with primary } \\
\text { infertility } \\
\text { Median (IQR) }\end{array}$ & $\begin{array}{c}\text { Patients with } \\
\text { secondary infertility } \\
\text { Median (IQR) }\end{array}$ & P value \\
\hline Estrogen & $157(125-232)$ & $176(125-272)$ & $141(118-162)$ & 0.018 \\
\hline Progesterone & $3.4(0.7-25.9)$ & $10(0.95-27)$ & $0.6(0.4-16)$ & 0.014 \\
\hline Follicle stimulating hormone & $4.9 \pm 1.3$ & $4.7 \pm 1.3$ & $5.2 \pm 1.3$ & 0.120 \\
\hline Leutinizing hormone & $4.8(3.2-6.8)$ & $5.1(3.4-7)$ & $3.9(2.7-5.4)$ & 0.613 \\
\hline Prolactin & $355(243-610)$ & $373(261-655)$ & $314(237-377)$ & 0.108 \\
\hline
\end{tabular}

* p-values were obtained using independent $t$ test if normally distributed or Mann-Whitney test for skewed variables. $\mathrm{P}<0.05$ was considered as significant.

Figure 1: The causes of infertility across the study population and by type of infertility

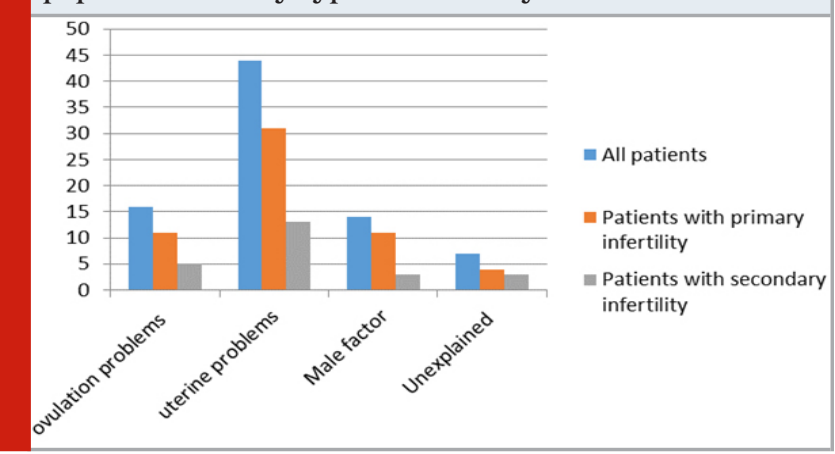

Figure 1 demonstrates the causes of infertility across the study population and by type of infertility. Uterine problem was the most common reason for infertility among all study populations, followed by ovulation problems, $54 \%$, and 20\%, respectively. The median level of estrogen among patients with primary infertility was higher than the median estrogen level of patients with secondary infertility (Table 2). The results showed that there is a statistically significant difference between the underlying distribution of the estrogen level of patients with primary infertility and the estrogen level of patients with secondary infertility $(z=2.35, p=0.018)$.

This was similar for progesterone level $(\mathrm{z}=2.56, \mathrm{p}=0.010)$. For the FSH, the mean level among all patients was 4.9(SD 1.3), the results indicate that there is no statistically significant difference between the mean level of FSH for primary infertility and secondary infertility $(\mathrm{t}=-1.57$, $\mathrm{p}=0.12$ ). For the remaining hormonal parameters, the median of LH and prolactin was higher in female with primary infertility compared with median level of those hormones in women with secondary infertility.

\section{DISCUSSION}

This study provides update evidence regarding the hormonal status among infertile Saudi females. The the overall rates of primary and secondary infertility were $57(70 \%)$ and $24(30 \%)$, respectively.

Previous studies have described the hormonal status among infertile female in different populations. The finding of those studies were similar to our finding $(19,20)$.We found that female with primary infertility were younger, and the duration of the marriage was, on average near five years. This suggested that there is a delay by the couples seeking the medical help which they require. The reasons for this could be multi-factorial. One which we believe is that the infertility treatment is expensive, and many patients may not be able to afford it; also, in the eastern province with a population of 4.1 million, there are no government hospitals which have IVF centers. Secondly, it was also suggested that these young couples may require pre-marital clinics, which unfortunately do not exist in Saudi Arabia.

Known that the obesity and overweight is the main health issue and is a common problem among women 
of reproductive age and both obesity and overweight involves an abnormal and excessive fat accumulation that negatively affects the health of the body (22), we observed that around 70\% of infertile female in this study were overweight and obese. There is an association between increased BMI and fertility among the female; therefore, weight loss could be one of the effective standard of treating infertility among obese women.

It is a well-known fact that the causes of primary and secondary infertility were not always a woman's problem, both males and females could be responsible for the causes of infertility, and most of the infertile couples have one of these three major causes including a male factor, ovulation dysfunction, or tubal-peritoneal disease $(23,20)$. This was consistence with our finding as we found that most reasons that led to fertility in this study caused by ovulation problem, uterine problem and male factors.

In addition, several factors can disturb the process of fertility especially among female that cased by hormonal disorders (24) and hormones such as estrogen, progesterone, prolactin, FSH and LH can greatly affect female fertility (17). Therefore the present study observed significant differences in estrogen and progesterone levels between primary and secondary infertile female ( $>$ > 0.05), while other hormone such as FSH, LH, and prolactin showed insignificant differences between types of infertility $(p<0.05)$.

This study is observational in nature and has some limitations that could limit the validity of the results. Firstly, the observational nature of the study can introduce bias due to unmeasured confounder. Additionally, the generalizability of this study limited because the data used for this study were from a single-center, which mainly represents the eligible people for treatment within NGHA. However, this study provides a descriptive step for the hormonal changes among the Saudi female population in which further studies could be directed to explore the association between different factors and infertility.

\section{CONCLUSION}

Applying of body mass index, duration of infertility and age of infertile female, could be of great value beside the routine laboratory test and other radiological tests for the diagnosis and classification of female infertility

Disclaimers/Disclosure: Authors have no conflict of interests, and the work was not funded.

We observed that patients with primary infertility were younger and the duration of the marriage was on average near 5 years. This suggests that there is a delay by the couples in seeking the medical help which they require.

\section{REFERENCES}

Abdelhafid Benksim, Noureddine Elkhoudri, Rachid Ait Addi, Abdellatif Baali, Mohamed Cherkaoui (2018). Difference between Primary and Secondary Infertility in Morocco: Frequencies and Associated Factors, Int J FertilSteril. ;12(2): 142-146

Abolfotouh M, Alabdrabalnabi, Albacker, Al-Jughaiman U, Hassan (2013). Knowledge, attitude, and practices of infertility among Saudi couples. International Journal of General Medicine. 6(1):563.

Achten, V., Bouckaert, G. and Schokkaert, E.. (2016) A truly golden handbook'. 1st ed. Leuven: Leuven University Press, 107.

Agarwal A, Mulgund A, Hamada A, Chyatte M (2015). A unique view on male infertility around the globe. Reproductive Biology and Endocrinology. 13(1):37.

Al-Turki HA. Prevalence of primaryand secondary infertility from tertiary center in eastern Saudi Arabia, Middle East Fertility Society Journal 2015;20(4): 237-240

Aoun T, Moawed S (2012). Effects of Environmental, Cultural, and Socioeconomic Factors on Saudi Infertile Couple in Riyadh City. Life Science Journal. 9(4):48614867.

Aoun T, Moawed S (2012). Effects of Environmental, Cultural, and Socioeconomic Factors on Saudi Infertile Couple in Riyadh City. Life Science Journal. 9(4):48614867.

Blaževiciene A, Jakušovaite I, Vaškelyte A (2014). Attitudes of fertile and infertile woman towards new reproductive technologies: a case study of Lithuania. Reprod Health. 11(1):26-26.

Gandomani S, Taebi M, Nilforoushan P, GholamiDehaghi A. Association between infertility factors and nonphysical partner abuse in infertile couples. Iranian Journal of Nursing and Midwifery Research. 2016;21(4):368.

Gurunath S, Pandian Z, Anderson RA, Bhattacharya S. Defining infertility-a systematic review of prevalence studies. Hum Reprod Update. 2011; 17(5):575-588.

Hamada A, Esteves S, Agarwal A. Unexplained male infertility: potential causes and management. Human Andrology. 2017;1(1):2-16.

Ikechebelu JI, Adinma JI, Orie EF, Ikegwuonu SO. High prevalence of male infertility in southeastern Nigeria. J ObstetGynaecol. 2003;23(6):657-659.

Indira M, Babu CS. Estrogen, Progesterone and Serum Prolactin Levels In Infertility Cases of Women. Journal of Dental and Medical Sciences. 2015;14(6):25.

Infertility defınitions and terminology. World Health Organization. Available from:http://www.who.int/ reproductivehealth/topics/infertility/definitions/en/ Jacky Boivin, Laura Bunting, John A. Collins, Karl G. Nygren. International estimates of infertility prevalence and treatment-seeking: potential need and demand for infertility medical care. Human Reproduction. 
2007;22(6): 1506-1512,

Kakarla N, Bradshaw K. Evaluation and Management of the Infertile. Glowm. 2008.

Kashani L, Akhondzadeh S. Female inferility and herbal medicine. Journal of medicine plants.2017;16(61):2

Kazerooni T, Dehghan-Kooshkghazi M. Effects of metformin therapy on hyperandrogenism in women with polycystic ovarian syndrome. GynecolEndocrinol. 2003;17(1):51-56.

Mohamed G, Mohammed M, Mosab M .The prevalence of cancer among selected group of Sudanese women with fertility problems. Global journal of medical research. 2018; 18(2):1.

Olooto, Wasiu Eniola; Amballi, Adebayo Adetola; and Banjo, Taiwo Abayomi.A review of Female Infertility; important etiological factors and management. Journal of Microbiology and Biotechnology Research.2012;2 (3):379-385

Stevenson, E., Hershberger, P. and Bergh, P. EvidenceBased Care for Couples with Infertility. Journal of Obstetric, Gynecologic \& Neonatal Nursing.2016; 45(1):100-110.

Tabong PT, Adongo PB. Infertility and childlessness: a qualitative study of the experiences of infertile couples in North Ghana. BMC Pregnancy Childbirth. 2013;13:72-72.

Winkelman, W., Katz, P., Smith, J. and Rowen, T. The Sexual Impact of Infertility among Women Seeking Fertility Care. Sexual Medicine.2016; 4(3): 190-197. ZeynepÖzcan Dag1, Berna Dilbaz2Impact of obesity on infertility in women, Journal of the Turkish- German Gynecological Association. 2015; 16(2): 111-117 